Article

\title{
Does Positive Relational Management Benefit Managers Higher Up the Hierarchy? A Moderated Mediation Study of New Zealand Managers
}

\author{
Jarrod Haar 1,*D, Annamaria Di Fabio ${ }^{2}$ and Urs Daellenbach ${ }^{3}(\mathbb{D}$ \\ 1 Department of Management, Auckland University of Technology, Auckland 1142, New Zealand \\ 2 Department of Education, Languages, Intercultures, Literatures and Psychology (Psychology Section), \\ University of Florence, 50121 Florence, Italy \\ 3 School of Management, Victoria University of Wellington, Wellington 6012, New Zealand \\ * Correspondence: jarrod.haar@aut.ac.nz
}

Received: 21 June 2019; Accepted: 6 August 2019; Published: 13 August 2019

\begin{abstract}
Interpersonal relationships play an important role in work success, and this is especially so for managers. The present study tests the Positive Relational Management (PRM) Scale and its influence on organizational trust, with the effects potentially mediated by work-life balance. Hence, more positive relationships at work shape better management of work-life issues, and ultimately build trust perceptions. We test this on a sample of $600 \mathrm{New}$ Zealand managers and include managerial hierarchy as a moderator to determine whether positive relationships become less important as management level increases. Ultimately, we test a moderated mediation model in PROCESS and confirm the dimensionality and reliability of the scale. We find PRM is positively related to work-life balance and organizational trust, while work-life balance partially mediates this effect. In addition to two significant two-way interactions, we find support for a moderated mediation effect, with the indirect effect of PRM being positive and strongest for low-level managers, but a reduction in the strength of the indirect effects for middle- and senior-managers. Hence, the importance of interpersonal relationships is especially powerful for low-level managers. The implications for understanding the importance of PRM for managers are discussed.
\end{abstract}

Keywords: positive relational management scale; work-life balance; organizational trust; management hierarchy; moderated mediation

\section{Introduction}

Di Fabio [1] stated that "work plays a key role in the health and well-being of workers" (p. 1), and that under today's workplace constraints, workers are under threat. This is especially true of managers and leaders, with Roche, Haar, and Luthans [2] stating, "currently, leaders at all levels of organizations are under ever increasing pressure because of the competitiveness and complexity of the global economy" (p. 476). This has led to the championing of healthy organizations $[1,3]$ to create healthier societies. However, while we know that challenging situations facing leaders [2] result in detrimental influences [2-6], we know much less about the potential positive side of antecedents that may shape leaders' outcomes [2]. Positive psychology offers a constructive approach to exploring positive factors towards positive outcomes [7,8], and while several different factors can be explored [9], we focus on interpersonal relationships, specifically the Positive Relational Management (PRM) Scale by Di Fabio [8].

Di Fabio [8] notes that interpersonal relationships are a fundamental resource for employees, where they can draw on the support and care of others, which builds their own personal resources, 
ensuring greater well-being and job focus. Hence, positive relationships mean that employees can create "optimal conditions to support adaptive relationships in organizational contexts" (Di Fabio, p. 1) [8], and this aligns well with positive psychology $[7,10]$ and especially with employees flourishing [11,12]. The well-being and happiness of workers refer to the third goal among the seventeen goals for sustainability and sustainable development [13] in terms of good health and well-being, ensuring healthy lives and promoting well-being for everyone at all ages. They represent a fundamental aim for the psychology of sustainability and sustainable development $[1,14,15]$, considering the importance of building resources and strengths [16-22]. In this framework, the psychology of harmonization [23] calls for a prevention perspective for harmonization, underlining the value of the primary prevention perspective of Di Fabio and Kenny $[18,19,24,25]$, which focuses on building strengths for promoting the well-being of individuals.

Our study makes four contributions. First, we extend recent research exploring the PRM Scale and its influence on well-being (e.g., [8,26,27]) and examine its influence towards organizational trust, to highlight the potential influence of positive interpersonal relationships on job attitudes. We focus on organizational trust because it is a less examined workplace attitude compared to job satisfaction and work engagement, and yet has been found to be related (but distinct) to these job attitudes. There is also meta-analytical support for consequences of trust, including more positive job performance and citizenship behaviors [28]. Second, we include work-life balance as a potential mediator due to its important role on employee attitudes [29] and as an employee outcome [30]. Furthermore, it has been found to act consistently as a mediator [29,31], and thus is useful for better understanding the potential process of influence from PRM. Third, we include managerial hierarchy as a moderator to test potential differences across managers in low, medium, and high managerial roles and then combine these to test for moderated mediation [32]. Finally, our sample is of New Zealand managers, which provides a distinct cultural and employment position difference to the current literature. Our study model is shown in Figure 1.

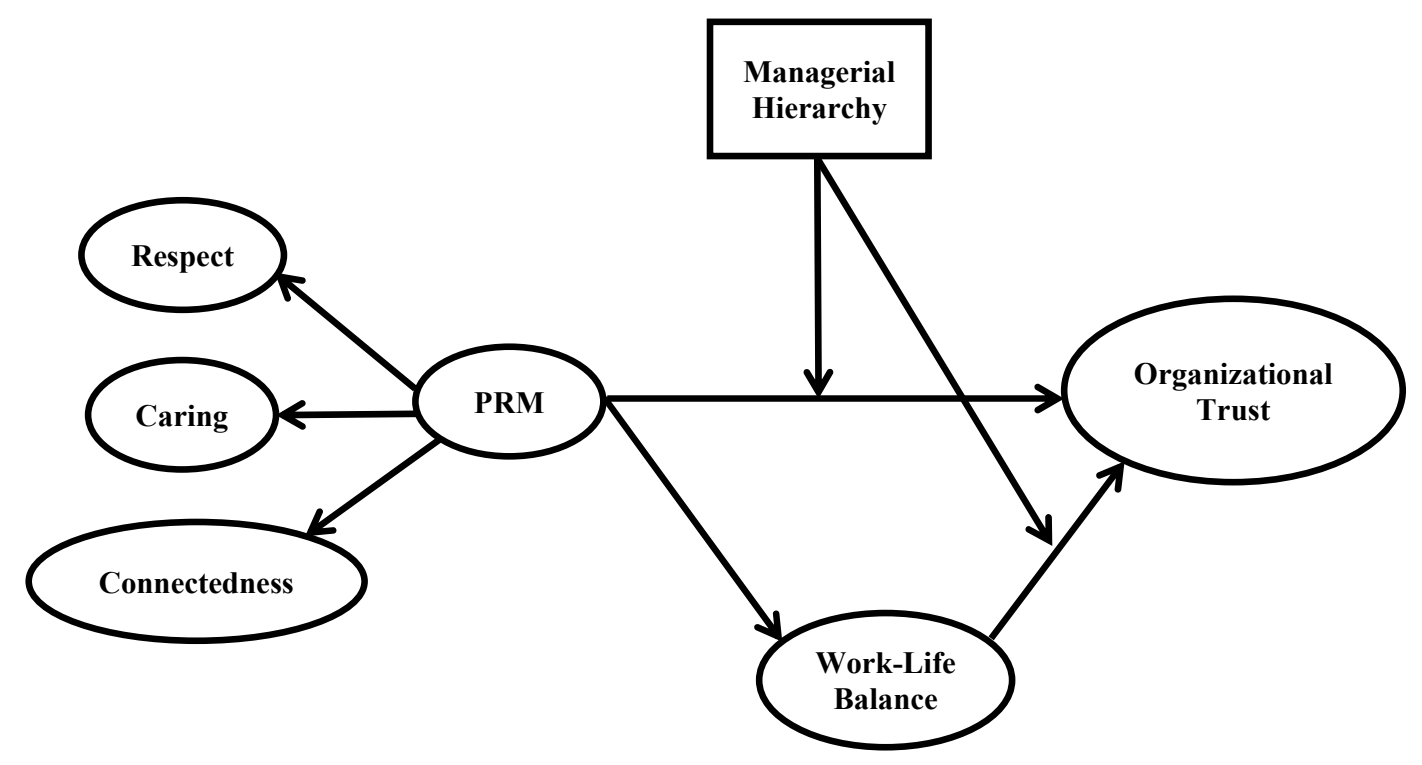

Figure 1. Study model.

\section{Positive Relational Management}

In alignment with positive psychology frameworks, Di Fabio [11] created the Positive Self and Relational Management (PS\&RM) model, which focuses on the positive lifelong development of the individual, with a specific positive focus on relationships with the self. Di Fabio and Kenny [18] note that positive relational management plays a central role in the PS\&RM model, due to its focus on self and relational management $[11,18]$. This is specifically in relation to social skills, relational 
skills, and social support, which build individual competencies to successfully manage workplace challenges [18]. The PRM Scale focuses on caring and respect as well as the relationships between people [33,34].

The PRM Scale $[8,34]$ builds on the conceptual importance of relationality, respect, and caring. Importantly, the focus is both on the self and others [33-35]. Di Fabio [8] defines the dimensions and specific details as: respect (my respect for others, the respect of others for me, my respect for myself), caring (my care for others, the care of others for me, my care for myself), and connectedness (my connectedness with family members, with friends, with significant others). Combined, these factors represent resources that employees can draw on $[18,33]$, which align with the Conservation of Resources (COR) framework [36,37].

Under the COR framework, Hobfoll [37] defined resources as, "those objects, personal characteristics, conditions, or energies that are valued in their own right, or that are valued because they act as conduits to the achievement or protection of valued resources" (p. 339). COR focuses on resources, and the way in which employees seek to acquire more, retain existing resources, and minimize resource loss where possible [36]. Resources are broadly interpreted, with Hobfoll [37] listing many examples, including positive feelings about the self, having companionship, working with similar others, and having co-worker support. The three dimensions of the PRM Scale align well with the COR theory and suggest that employees experiencing greater PRM at work will enjoy more resources, to facilitate optimum performance.

In support of this resources approach, PRM has been found to relate positively to well-being outcomes, including life satisfaction, life meaningfulness, positive and negative affect, and flourishing $[8,18]$, which align with studies which have found that positive relationships can influence well-being [38]. Hence, through higher levels of respect, caring, and connectedness from work interactions, employees accumulate superior resources, and this enables them to expend fewer resources to achieve higher well-being. Under these theoretical linkages, it is expected that PRM will similarly provide greater job outcomes, because individuals with higher resources [36,37] have the resources to generate a superior performance. We now explore the work outcomes for our study.

\section{Organizational Trust}

Trust can take multiple forms [39], including an attitude [40]. Robinson [41] defined trust as, "one's expectations, assumptions, or beliefs about the likelihood that another's future actions will be beneficial, favorable, or at least not detrimental to one's interests" (p. 576). Trust is one of the most studied constructs in the organizational literature [42], although it has not been explored regarding PRM. Guerrero and Herrbach [43] stated that, "trust in the organization is at the heart of the social exchange process" (p. 6), and thus receiving respect, caring, and connectedness from workplace interactions might also trigger social exchange reactions, whereby employees reciprocate benefits received at work [44], with such reactions triggering felt obligations [45]. This results in fewer destructive behaviors and greater constructive behaviors, like enhanced citizenship behaviors and improved task performance [28].

Consequently, having co-workers that provide caring and respect can cause employees to feel obligated to reciprocate [44-47], for example, by showing greater trust in their organization. Beyond social exchange theory, PRM can build the psychological resources of employees at work, and thus under COR theory, they will also enable stronger resources to be reflected across job attitudes, like organizational trust. This is because the additional resources provided by PRM to employees provides them with additional psychological resources to invest in their work and related attitudes, like trust perceptions. Hence, higher positive relationships can help build organizational trust. Thus, we posit the following.

Hypothesis 1. PRM will be positively related to organizational trust. 


\section{Work-Life Balance}

Haar [29] defined work-life balance as, "the extent to which an individual is able to adequately manage the multiple roles in their life, including work, family, and other major responsibilities" (p. 3308). Hence, work-life balance reflects a strong positive alignment between work and non-work roles, which aligns with PRM, which includes the self, colleagues, and personal connections. While research has found work-life balance is an important predictor of job and well-being outcomes [30,31,48,49], including in international samples [31], there is limited knowledge about the antecedents of work-life balance and, indeed, no exploration of PRM. Haar, Sune, Russo, and Ollier-Malaterre [50] found work and family factors influenced work-life balance, including supervisor support. However, that study did not explore broader forms of support from co-workers or family, nor did it focus upon the dimensions of PRM-specifically respect, caring, and connectedness from interpersonal interactions.

Work-life balance is best understood using a person-centric approach, where an employee's own perception of how successfully they manage their many roles is the central approach [29-31,51]. Hence, it is not whether someone works too long or too little that determines work-life balance, but rather how they perceive their ability to manage all life roles that is important. This approach concurs with Barnett and Hyde [52], who argued it is the successful balancing of roles rather than the overall number of roles that is important under work-life balance perceptions. Under COR theory, employees with stronger PRM will have additional resources that should enable them to balance their work and non-work roles in a superior manner, leading to better work-life balance. This is because the support of co-workers and subordinates might facilitate emergency childcare issues or other non-work issues that can build work-life balance. In addition, friendly, supportive work from subordinates might make the manager feel more valued and respected, building their energy, which, under COR theory, they can subsequently invest into managing their work and non-work roles [29]. Thus, we posit the following.

Hypothesis 2. PRM will be positively related to work-life balance.

Beyond the direct effects of PRM towards work-life balance, we also explore work-life balance as a mediator of the influence of PRM on organizational trust. Work-life balance has been linked to several important employee outcomes, including job satisfaction [29,31,49,53], work engagement [30,54], and turnover intentions [53]. Importantly, there is strong evidence to show that work-life balance mediates the influence of other work factors, including leadership styles [53,54], work-family enrichment [29,30], work-family conflict [29-31], and pay fairness [49]. Hence, there is strong evidence for work-life balance functioning as a vital link in the process chain of effects towards employee attitudes. Despite the wide range of outcomes explored, there has been no exploration of work-life balance on organizational trust. In the context of the present study, we expect employees with greater psychological resources from enjoying better work-life balance to report higher organizational trust.

Such a direct effect from work-life balance is expected because this reflects the additional resources available to the employee under COR theory [37] through enhanced PRM, and this also aligns with the role balance theory [29], regarding the benefits of better work-life balance enhancing employee performance. These effects also ally with social exchange theory [47], whereby employees might reflect the organizational support they have received at work, helping them achieve superior work-life balance, and in turn, reciprocate with stronger trust perceptions. Ultimately, the COR theory suggests that resources can be cumulative and enhance attitudes and behaviors, and here we test this as a process model. Here, we expect PRM to provide additional resources that enhance managers' work-life balance, and in turn, they will use this greater work-life balance (and associated resources) to invest in greater organizational trust perceptions. Thus, we expect work-life balance to not only directly influence organizational trust, but also mediate the influence of PRM on organizational trust. We posit the following.

Hypothesis 3. Work-life balance will be positively related to organizational trust. 
Hypothesis 4. Work-life balance will mediate the influence of PRM to organizational trust.

\section{Managerial Hierarchy}

Beyond the direct and mediated relationships expected here, we also explore managerial hierarchy as a moderator of the effectiveness of relationships, including moderation on the mediated pathways. We use the managerial hierarchy to reflect managerial positions as they occur-from low to high-thus, reflecting the associated power, prestige, and resources that go along with such positions. Jaques [55] noted that managerial hierarchy is a natural occurrence of organizational life, which can reflect the layers of management within an organization. Roche and Haar [56] suggested that senior managers-those at the highest range of the managerial hierarchy-have the greatest responsibility, but also potentially the highest pressures [57]. Jaques [55] reflected that the managerial hierarchy has control and responsibility over those working under that hierarchy and, thus, is naturally entwined with leadership. While this type of hierarchical authority reflects the power of leadership [58], in the present study we use it to reflect on the access to resources available to managers. This is because Warr [59] noted that managers can have greater freedom, decision-making latitude, and control over their work, which under the COR theory makes managerial hierarchy advantageous. In the present study, we suggest that managerial hierarchy will moderate the effects of PRM and work-life balance on organizational trust, such that the effects of managerial hierarchy will be especially beneficial to senior managers, rather than low-level and middle-managers. Hence, those in senior positions, with additional resources at their disposal, are likely to leverage the resource gains from PRM and work-life balance better.

However, beyond the two-way moderating effects, we also explore managerial hierarchy as a moderator of the PRM-work-life balance-organizational trust relationship. Hence, the managerial hierarchy is expected to act as a boundary condition, whereby the effectiveness of PRM on organizational trust (via work-life balance as the mediator) is expected to fluctuate with levels of managerial hierarchy. Hayes [32] calls this moderated mediation, or conditional process modelling, and defined it as, "an analytical strategy focused on quantifying the boundary conditions of mechanisms and testing hypotheses about the contingent nature of processes ... whether an indirect effect (mediation) is dependent on another variable (moderation)" (p. 5). Muller et al. [60] suggested that moderated mediation implies that the indirect effect-here, PRM and its influence on organizational trust through work-life balance-is dependent on managerial hierarchy. Overall, [60] stated, "in sum, for mediated moderation, there is overall moderation, produced by the mediating process, and when this process is controlled, the residual moderation of the treatment effect is reduced" (p. 856). Here, we expect senior managerial positions will report weaker indirect effects from PRM because, in effect, the importance of respect, caring, and connectedness is likely to be less vital when managers have additional roles and resources to draw upon. Hence, we expect a negative moderated mediation effect, whereby the indirect effect of PRM weakens as managers get higher up the hierarchy. Thus, we posit the following two-way and moderated-mediated hypotheses.

Hypothesis 5. Managerial hierarchy will moderate the influence of (a) PRM and (b) work-life balance on organizational trust.

Hypothesis 6. The indirect relationship between PRM and organizational trust via work-life balance will be moderated by managerial hierarchy, such that the indirect effect of PRM becomes weaker as the managerial hierarchy gets stronger (moderated mediation).

\section{Methods}

\subsection{Participants and Sample}

Data were collected from 600 private sector New Zealand managers, recruited via a Qualtrics survey panel. In the present context, Qualtrics has access to thousands of New Zealand employees 
and specifically targeted and invited managers to participate in the study. They came from the broadest range of firms by sector, industry, location, and size. The survey confirmed the roles and sector of participants and then captured their managerial hierarchy level. Respondents who replied to their managerial position as supervisor were also removed. The Qualtrics' system is quality focused and removed respondents who completed the survey too fast or too slow and ensured there were no multiple respondents. This methodological approach has produced good employee samples (e.g., Haar et al. [49]). Respondent firms were, on average, 25 years old (SD $=23.2$ years), with an average size of 625 employees ( $S D=2664)$, and across a wide range of industries-from mining and primary sector, to manufacturing, retail, and professional services. Manager respondents were, on average, aged 39.5 years $(\mathrm{SD}=12.3)$, and were highly educated: $21.2 \%$ postgraduate qualifications, $40.7 \%$ university degree, $23.2 \%$ technical qualification, and $15.0 \%$ high school qualification. Managers had 7.7 years job tenure $(S D=5.8)$ and were well spread across managerial hierarchy: $34.3 \%$ senior managers/executives, $41.7 \%$ middle-level managers, and $24.0 \%$ low-level managers.

\subsection{Measures}

PRM was measured using the 12 -item scale by Di Fabio [8], coded $1=$ strongly disagree, $5=$ strongly agree. The construct has three dimensions: (1) respect, sample item-“I have respect for the value and uniqueness of others"; (2) caring, sample item- "I often take care of others"; and (3) connectedness, sample item-“I have good relationships with my friends". We followed Di Fabio [8] and combined items for a single construct, and the PRM construct had very good reliability $(\alpha=0.89)$. This construct has been validated [26].

Work-life balance was measured using Haar's [29], three-item measure, coded $1=$ strongly disagree, $5=$ strongly agree. A sample item is, "nowadays, I seem to enjoy every part of my life equally well". The reliability was very good $(\alpha=0.86)$. This construct has been validated across New Zealand employees [53,54], including the working poor [49], international employee samples [31], and at the daily-diary level [30].

Organizational trust was measured using three items by Robinson [41], coded $1=$ strongly disagree, $5=$ strongly agree. Sample items include, "my employer is open and upfront with me", and the construct had very good reliability $(\alpha=0.89)$.

Managerial hierarchy was calculated from the self-reported manager position given by respondents, coded 1 = low-level manager, 2 = middle-level manager, 3 = senior manager/executive.

We controlled for firm size (total number of full-time employees), and manager demographics of age (in years), education $(1=$ high school, $2=$ technical college, $3=$ university degree, and $4=$ postgraduate qualifications), and job tenure (in years). We expected large-sized firms were likely to have more financial resources and thus may provide greater benefits that aid trust perceptions [61,62]. We controlled for age due to meta-analytic findings that older workers report more positive job attitudes [63], and similarly so for job tenure, as it has been related to better mental health [4]. Finally, there is also meta-analytics support for higher educated workers having stronger work aspects [64].

Measurement Models: We confirmed the nature of the various study constructs using confirmatory factor analysis (CFA) in Structural Equation Modelling with AMOS version 25. For SEM studies, Williams, Vandenberg, and Edwards [65] recommend the following goodness-of-fit indexes and their thresholds: (1) the comparative fit index (CFI $\geq 0.95)$, (2) the root-mean-square error of approximation (RMSEA $\leq 0.08$ ), and (3) the standardized root mean residual (SRMR $\leq 0.10$ ). We tested eight alternative CFAs to determine if the theoretically-derived constructs fit the data best-these are shown in Table 1 .

Overall, the hypothesized measurement model was the best fit for the data: $\chi^{2}(\mathrm{df})=386.3$ (125), CFI $=0.95$, RMSEA $=0.06$, and SRMR $=0.04$, with the alternative measurement models resulting in poorer fit-all $p<0.001$ [66]. While work-life balance was highly correlated with PRM and organizational trust, the alternative CFA models showed that these constructs were a much better fit to the data individually. 
Analysis: Relationships were tested using PROCESS 3.1 (in SPSS v. 25), specifically model 15 (moderated mediation). Control variables were entered in Step 1, with PRM entered as the independent variable, work-life balance as the mediator variable, and organizational trust as the dependent variable. Managerial hierarchy was entered as the moderator variable, the products were mean-centered, and bootstrapping (5000 times) was used to confirm the existence of mediation effects, with confidence intervals [LL=Lower Limit, UL=Upper Limit]. An examination of the skewness and kurtosis statistics indicated that each of these was within acceptable limits [66]. The PROCESS output files provided data points for moderation to aid graphing effects, while the index of moderated mediation provided indirect effects (and confidence intervals) at low, average, and high levels of the moderator (-2SD, Mean, +2SD). See [67] for an example.

Table 1. Results of confirmatory factor analysis.

\begin{tabular}{cccccccccc}
\hline & \multicolumn{4}{c}{ Model Fit Indices } & \multicolumn{3}{c}{ Model Differences } \\
\hline Model & $\boldsymbol{\chi}^{\mathbf{2}}$ & df & CFI & RMSEA & SRMR & $\boldsymbol{\Delta} \mathbf{\chi}^{\mathbf{2}}$ & $\boldsymbol{\Delta d f}$ & $\boldsymbol{p}$ & Details \\
\hline Model 1 & 386.3 & 125 & 0.95 & 0.06 & 0.04 & & & & \\
Model 2 & 439.8 & 129 & 0.94 & 0.06 & 0.04 & 53.5 & 4 & 0.001 & Model 2 to 1 \\
Model 3 & 544.7 & 129 & 0.93 & 0.07 & 0.05 & 158.4 & 4 & 0.001 & Model 3 to 1 \\
Model 4 & 456.5 & 129 & 0.94 & 0.07 & 0.05 & 70.2 & 4 & 0.001 & Model 4 to 1 \\
Model 5 & 573.9 & 132 & 0.92 & 0.08 & 0.05 & 187.6 & 7 & 0.001 & Model 5 to 1 \\
Model 6 & 946.6 & 129 & 0.85 & 0.10 & 0.07 & 560.3 & 4 & 0.001 & Model 6 to 1 \\
Model 7 & 896.8 & 129 & 0.86 & 0.10 & 0.06 & 510.5 & 4 & 0.001 & Model 7 to 1 \\
Model 8 & 636.3 & 129 & 0.91 & 0.08 & 0.07 & 250.0 & 4 & 0.001 & Model 8 to 1 \\
Model 9 & 851.5 & 129 & 0.87 & 0.10 & 0.06 & 465.2 & 4 & 0.001 & Model 9 to 1 \\
\hline
\end{tabular}

Model 1 = Hypothesized five-factor model: PRM Respect, PRM Caring, PRM Connectedness, Work-life Balance and Organizational Trust.

Model 2 = Alternative four-factor model: As per model 1, with PRM Respect and PRM Caring combined.

Model 3 = Alternative four-factor model: As per model 1, with PRM Respect and PRM Connectedness combined.

Model 4 = Alternative four-factor model: As per model 1, with PRM Caring and PRM Connectedness combined.

Model 5 = Alternative three-factor model: As per model 1, with PRM Respect, PRM Caring and PRM Connectedness combined.

Model 6 = Alternative four-factor model: As per model 1, with Work-life Balance and Organizational Trust combined.

Model 7 = Alternative four-factor model: As per model 1, with PRM Respect and Work-life Balance combined.

Model 8 = Alternative four-factor model: As per model 1, with PRM Caring and Work-life Balance combined.

Model 9 = Alternative four-factor model: As per model 1, with PRM Connectedness and Work-life Balance combined.

\section{Results}

Descriptive statistics for the study variables are shown in Table 2.

Table 2. Correlations and descriptive statistics of study variables.

\begin{tabular}{|c|c|c|c|c|c|c|c|c|c|c|}
\hline Variables & $\mathbf{M}$ & SD & 1 & 2 & 3 & 4 & 5 & 6 & 7 & 8 \\
\hline 1. Firm Size & 625.9 & 2675 & - & & & & & & & \\
\hline 2. Age & 39.5 & 12.3 & -0.05 & - & & & & & & \\
\hline 3. Education & 2.7 & 0.97 & 0.05 & $-0.11^{* *}$ & - & & & & & \\
\hline 4. Job Tenure & 7.7 & 5.8 & -0.01 & $0.51^{* *}$ & 0.01 & - & & & & \\
\hline 5. Managerial Hierarchy & 2.1 & 0.76 & -0.08 & $0.24^{* *}$ & $0.14^{* *}$ & $0.24^{* *}$ & - & & & \\
\hline 6. PRM & 3.9 & 0.58 & -0.04 & 0.06 & -0.08 & 0.06 & -0.07 & - & & \\
\hline 7. Work-Life Balance & 3.7 & 0.84 & $-0.11^{* *}$ & 0.02 & -0.03 & 0.01 & $0.08 *$ & $0.58^{* *}$ & - & \\
\hline 8. Organizational Trust & 3.9 & 0.90 & -0.04 & 0.10 * & -0.02 & 0.05 & $0.15^{* *}$ & $0.53 * *$ & $0.53^{* *}$ & - \\
\hline
\end{tabular}

Table 2 shows that PRM was significantly correlated with work-life balance $(\mathrm{r}=0.58, p<0.01)$ and organizational trust $(\mathrm{r}=0.53, p<0.01)$, and work-life balance was significantly correlated with firm size $(\mathrm{r}=-0.11, p<0.01)$, managerial hierarchy $(\mathrm{r}=0.08, p<0.05)$, and organizational trust $(r=0.53, p<0.01)$. Managerial hierarchy was significantly correlated with age $(r=0.24, p<0.01)$, 
education $(\mathrm{r}=0.14, p<0.01)$, job tenure $(\mathrm{r}=0.24, p<0.01)$, and organizational trust $(\mathrm{r}=0.15, p<0.01)$, and organizational trust was also correlated significantly with age $(\mathrm{r}=0.10, p<0.05)$.

The results of the moderated mediation regression are presented in Figure 2.

The results show that PRM was significantly related to both work-life balance ( $\beta=0.84(0.05)$, $p=0.0000[\mathrm{LL}=0.75, \mathrm{UL}=0.93])$ and organizational trust $(\beta=0.80(0.05), p=0.0000[\mathrm{LL}=0.70$, $\mathrm{UL}=0.91]$ ), supporting Hypotheses 1 and 2 . Furthermore, work-life balance was significantly related to organizational trust $(\beta=0.41(0.04), p=0.0000[\mathrm{LL}=0.33, \mathrm{UL}=0.50])$, and when included in the model it partially mediated the effect of PRM on organizational trust ( $\beta=$ drops to $0.45(0.06), p=0.0000$ $[\mathrm{LL}=0.33, \mathrm{UL}=0.57])$. These findings support Hypotheses 3 and 4 . Managerial Hierarchy was also found to interact significantly with PRM to organizational trust $(\beta=0.30(0.08), p=0.0003[\mathrm{LL}=0.13$, $\mathrm{UL}=0.45])$ and with work-life balance to organizational trust $(\beta=-0.23(0.08), p=0.0013$ [LL $=-0.37$, $\mathrm{UL}=-0.08])$. This supports Hypothesis 5. Finally, the results of the index of moderated mediation were found to be significant (Index $=-0.23(0.08), p=0.0013$ [LL $=-0.37, \mathrm{UL}=-0.08]$ ). Hayes [32] indicates the interpretation to mean the indirect effect of PRM on organizational trust (mediated through work-life balance) differs between respondents working in different managerial hierarchies. We present the graphed interactions to illustrate the effects in Figures 3-5.

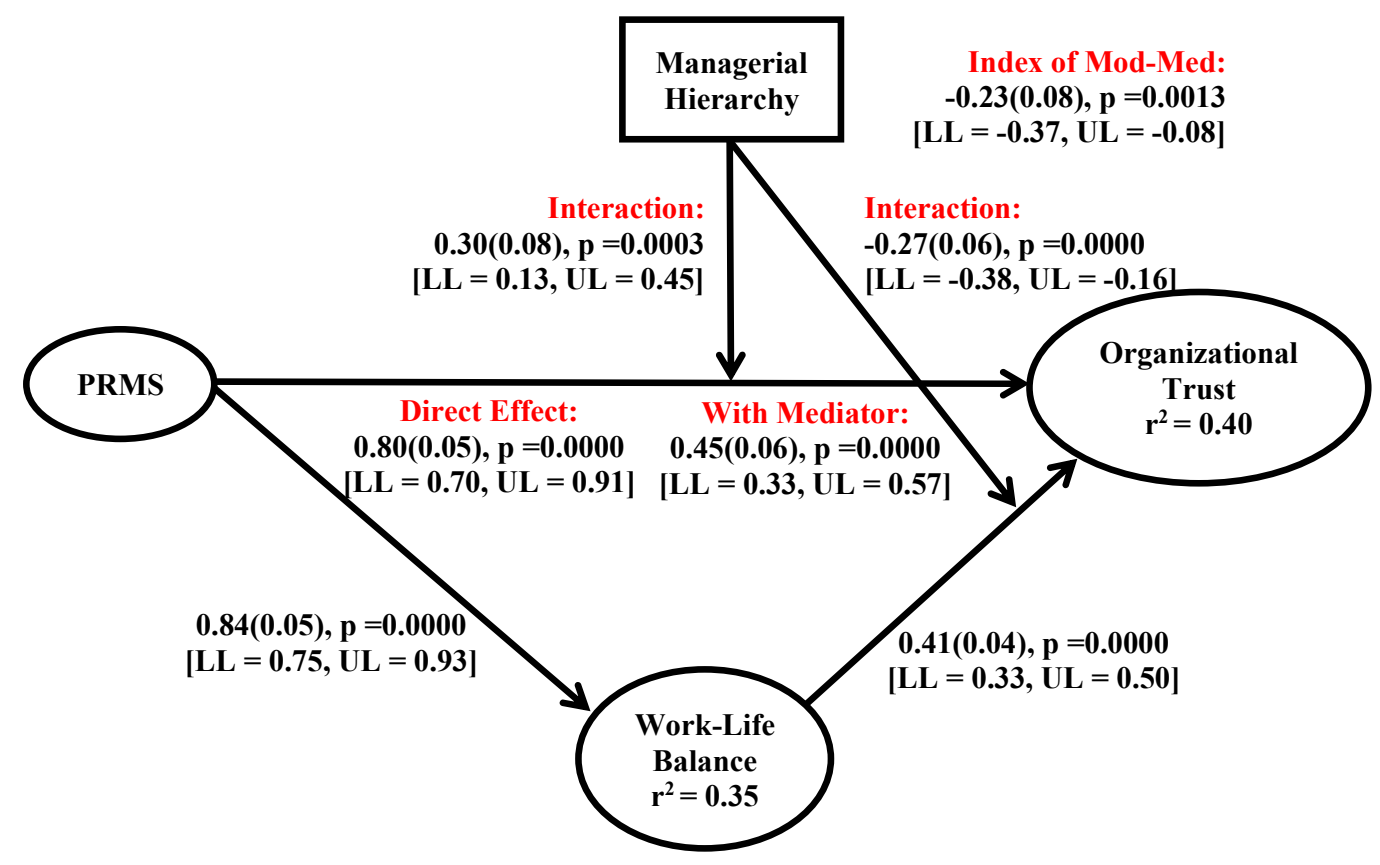

Figure 2. Final study model with moderation and mediation effects.

The significant two-way interaction in Figure 3 shows that at low levels of PRM, the influence on organizational trust was similar for respondents in low or high managerial hierarchy positions. When we compared respondents at high levels of PRM, both groups of respondents reported higher levels of organizational trust, but the group with the highest organizational trust was reported by respondents in high managerial hierarchy roles. This supports the hypothesized effect. The other significant two-way interaction (Figure 4) shows that at low levels of PRM, the influence on organizational trust was quite distinct, with respondents in high managerial hierarchy positions reporting significantly higher organizational trust. When we compared respondents at high levels of PRM, both groups of respondents reported higher levels of organizational trust, but the group with the highest organizational trust (and steepest increase) was reported by respondents in low managerial hierarchy roles. This effect is against that hypothesized. 


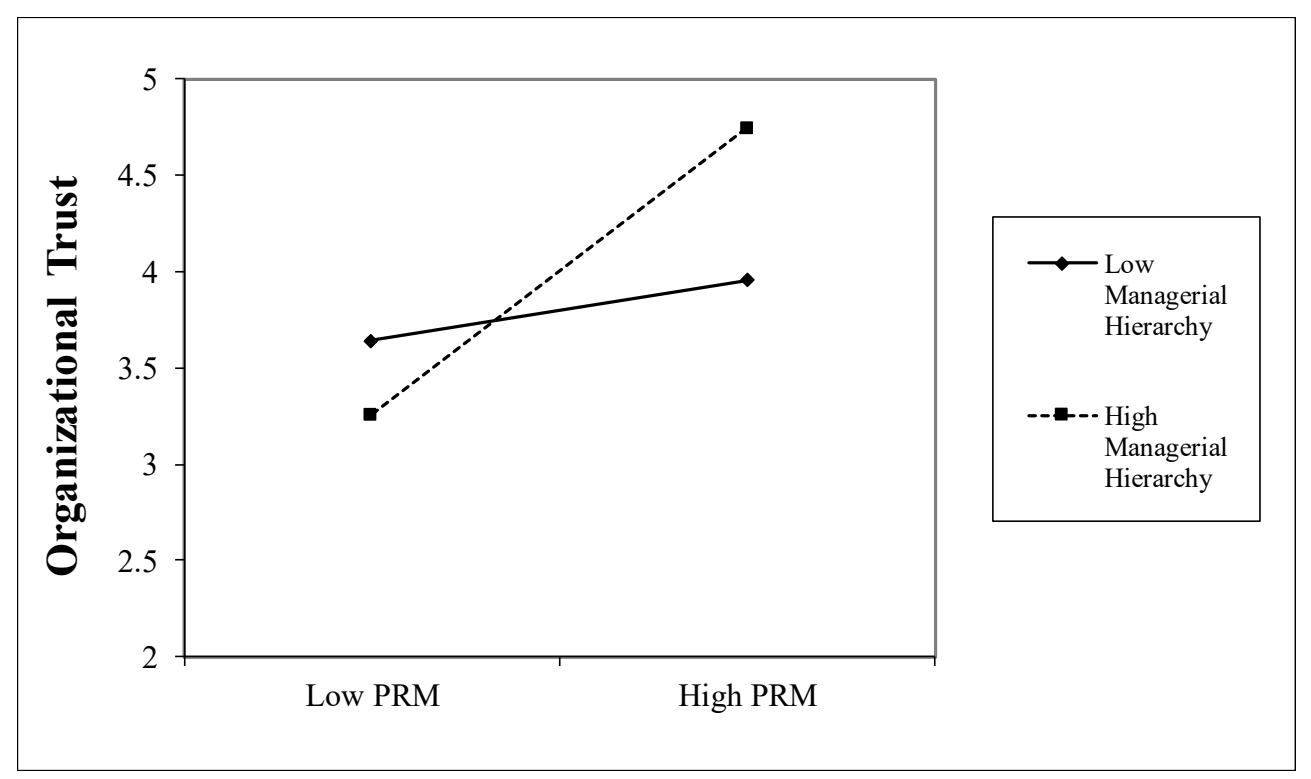

Figure 3. Interaction Effects of Managerial Hierarchy on Positive Relational Management (PRM) with organizational trust as the dependent variable.

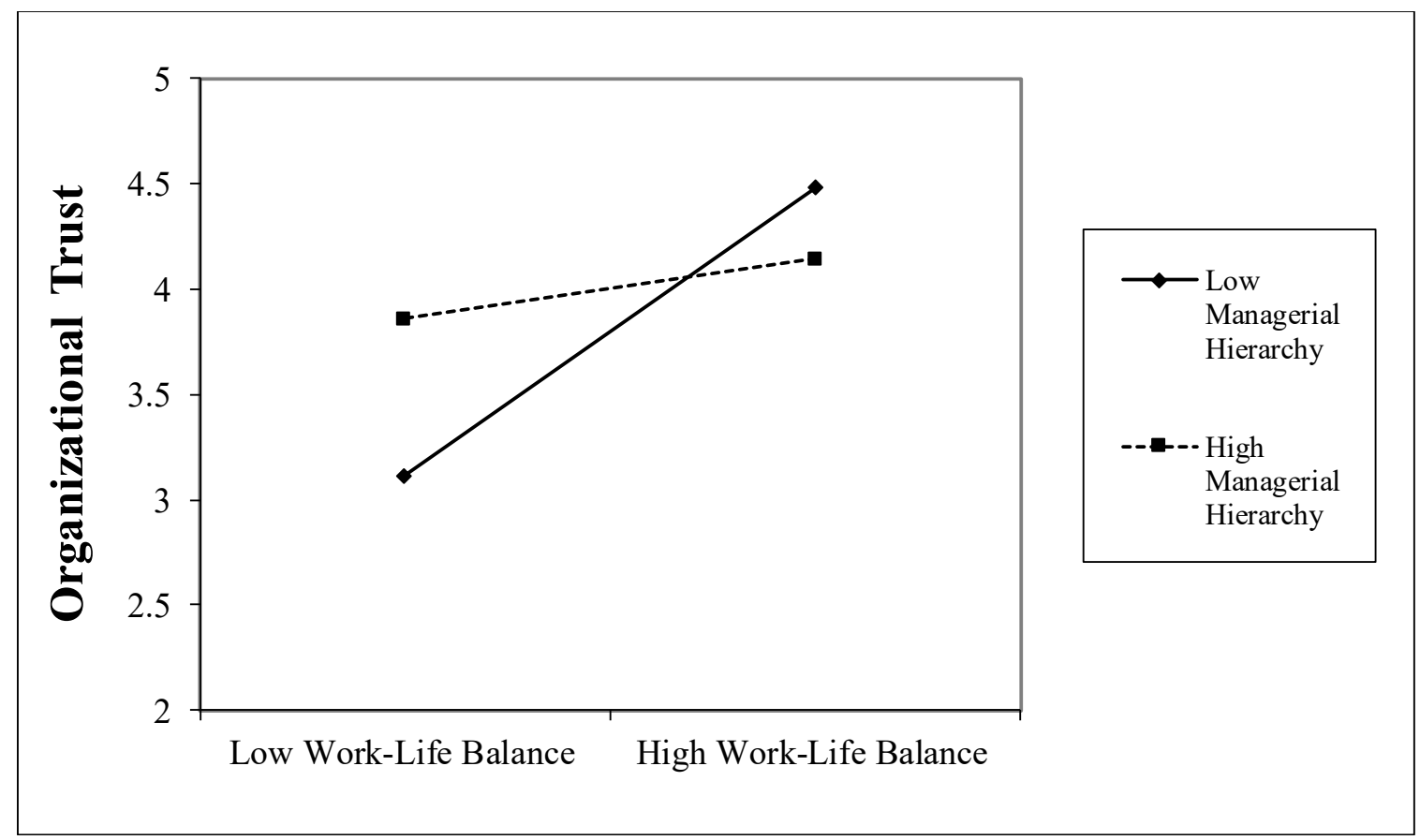

Figure 4. Interaction Effects of Managerial Hierarchy on Work-life balance with organizational trust as the dependent variable. 


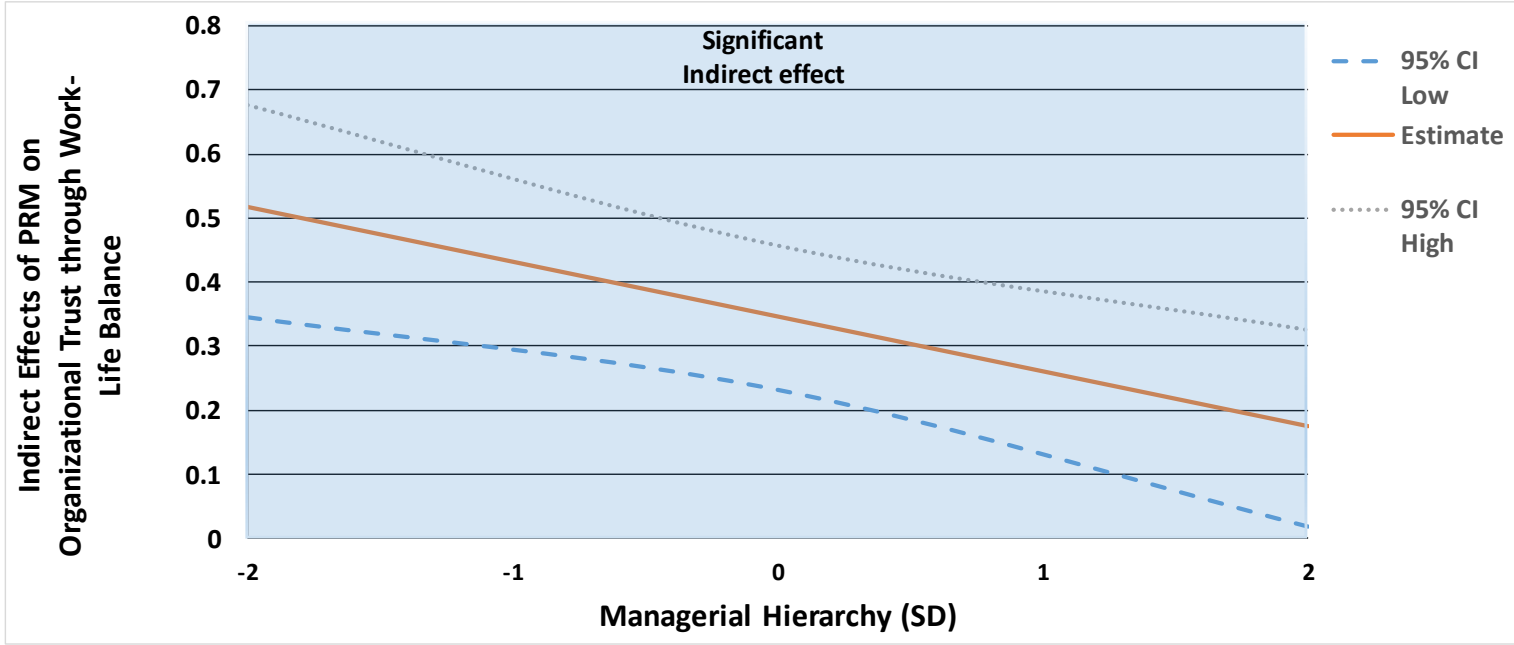

Figure 5. Indirect effects of PRM on organizational trust through work-life balance, conditional on managerial hierarchy.

Regarding the moderated mediation effect in Figure 5, we followed Wayne, Lemmon, Hoobler, Cheung, and Wilson [68] to probe the conditional indirect effect. Hence, we examined the magnitude and significance of the indirect effect of PRM on organizational trust through work-life balance, conditional on managerial hierarchy position (at -2SD, mean, and +2SD). We found that, for those respondents in the lowest managerial hierarchy (low-level managers), the effect of PRM on organizational trust vis-à-vis work-life balance was significant and strongly positive (estimate $=0.52(0.08), p=0.0000$; $[\mathrm{LL}=0.35$; $\mathrm{UL}=0.68]$ ). On the other hand, for those respondents at the mean (middle-managers), the effect of PRM on organizational trust vis-à-vis work-life balance was significant, positive, and modest (estimate $=0.35(0.06), p=0.0000 ;[\mathrm{LL}=0.23$; $\mathrm{UL}=0.46]$ ). Finally, those respondents at the $+2 \mathrm{SD}$ (senior managers) reported the effect of PRM on organizational trust vis-à-vis work-life balance as significant, positive, but weak (estimate $=0.18(0.08), p=0.0109$; $[\mathrm{LL}=0.02 ; \mathrm{UL}=0.32]$ ). This shows that as managers get higher up the managerial hierarchy, the positive indirect effect from PRM on organizational trust through work-life balance weakens. The moderated-mediation effect shows that the indirect effects of PRM start very strong but weaken considerably as managers progress up the position hierarchy. This supports Hypothesis 6.

Overall, across the control variables, none were significantly related to organizational trust. Finally, the model accounted for a robust amount of variance towards work-life balance (35\%) and organizational trust $(40 \%)$.

\section{Discussion}

The present study sought to understand the importance of relationships on the well-being and job attitudes of managers in New Zealand private sector firms. Di Fabio and Kenny [27] highlighted the importance of relationships, with employees rating it the second highest important factor to decent work, behind remuneration. Indeed, Di Fabio [14] argued the importance of work in the role of the health and well-being of workers, and the data from Di Fabio and Kenny [27] highlighted the importance of positive interactions between colleagues and leaders. We focused on managers, due to Roche et al. [2] highlighting the stress and pressures leaders were under, and thus we aligned our study using PRM to that of examining healthy organizations [1,3]. Here, we suggested that healthy organizations-that foster and encourage positive relationships (respect, caring and connectedness) between managers and others, others and the manager, as well as these aspects to themselves-would provide fundamental building blocks towards building manager well-being.

We found that PRM as a concept of positive relationships held in our sample of New Zealand managers, which is important, as the PRM construct has been chiefly tested within the Italian workspace 
(e.g., $[8,18,19])$. Our findings support the influence of PRM on organizational trust, which extends the outcomes tested to date, plus also work-life balance, which has been found to be an important predictor of job attitudes and well-being outcomes $[29,31,49,53,54]$. Hence, under the COR theory, we found support for the theoretical notion that positive relationships (PRM) help build psychological resources for managers, which enables them to build a stronger work-life balance and ultimately better perceptions of organizational trust. Importantly, we also tested and found support for work-life balance mediating the influence of PRM. However, this effect, while significant, was only partial mediation, and the remaining effect size of PRM on organizational trust highlights the importance and strength of positive relationship on job attitudes.

In addition, we also tested the influence of managerial hierarchy to understand the potential benefit-or reducing need - of positive relationships for managers across a range of positional hierarchies. We suggested that those with the highest managerial hierarchy might have the greatest pressures [56], but, importantly, greater control and freedom [55,57] which reflects the power of leadership [58]. In the present study, we used this to reflect on the access to resources available to managers. Indeed, what we found was that senior executives (highest managerial hierarchy) reported the strongest organizational trust perceptions when they also reported the strongest PRM. Hence, the importance of positive relationships is especially valid for senior managers. However, as expected, when we examined PRM in the context of work-life balance, mediating the influence towards organizational trust, it was lower-level managers who benefitted the most from PRM, likely reflecting that senior managers/executives have additional resources and freedom they can leverage to better achieve their organizational trust.

Overall, the present study makes several contributions. Beyond the internationalization of PRM and perhaps giving strength to the universal nature of positive relationships, we also provide theoretical and empirical evidence around the pathway of influence that positive relationships may work through. Furthermore, we found evidence that managerial hierarchy can act as a boundary condition, which has previously been unknown. The potentially conflicting evidence-whereby senior managers report the highest organizational trust directly from PRM but a significantly lower effect than that of junior leaders, when we consider the role of work-life balance-highlights the technical nature and complexity of positive relationships. We suggest that this simply highlights the complexities and potential power advantages [57] that managers enjoy as they progress up the managerial hierarchy, and we encourage researchers focusing on managers to consider their status or position in future research.

\subsection{Implications and Future Research}

The implications for these findings are that managers can build psychological resources and thus enhance their work-life balance and organizational trust perceptions through positive relationships (PRM). Thus, providing opportunities for interactions and positive relationships is likely to be especially valuable, not only for managers, but also their subordinates and significant others in their lives. This aligns well with work-life balance too [29]. Future research might examine these relationships towards other job attitudes and behaviors, like job satisfaction, turnover intentions, and citizenship behaviors, as well as additional well-being outcomes, like anxiety and depression, which have been found to be lower when employees report better work-life balance [29,31]. Furthermore, additional studies examining the potential boundary condition of managerial hierarchy are encouraged.

\subsection{Limitations}

While we had a relatively large sample $(n=600)$, this data was cross-sectional. However, Haar et al. [31] argue that conducting higher-level statistical analysis (CFA in AMOS) minimizes the potential of common method variance (CMV). Furthermore, Evans [69] conducted Monte Carlo simulations and identified that CMV issues are rare if moderation effects are found, and in the present study all three moderation effects were significant. Thus, given our findings, we suggest CMV is unlikely. Furthermore, regarding data analysis and CMV, Hayes, Montoya, and Rockwood [70] noted 
through alternative program testing that the PROCESS analysis produced near-identical findings to SEM. They suggest this indicates the analysis with PROCESS is robust, and our findings included confidence intervals and bootstrapping for mediation effects, which provides enhanced confidence.

Despite this, we followed recommendations by Podsakoff, MacKenzie, Lee, and Podsakoff [71] and conducted the Lindell and Whitney's [72] procedure (a partial correlation controlling for an unrelated construct). We controlled for the respondents' individual narcissism (three-items from Raskin and Terry [73], $\alpha=0.89$ ) and no change on the strength of correlations was found. This suggests that CMV is not evident. In addition, we re-analyzed the data to examine whether work-life balance functions better as an antecedent and with PRM as a mediator. Overall, in this model, there was little evidence of PRM mediating the effect of work-life balance on organizational trust, which was much more strongly supported in the hypothesized model. This suggests our hypothesized model does provide stronger alignment with the COR theory, although we acknowledge that given the cross-sectional nature of our data, the distinction between PRM as an antecedent or mediator might be modest. Further time-lagged analysis (e.g., [71]) is required to provide additional confidence. In summary, we had a large sample of managers across a wide range of industries and, given the above aspects, we suggest these findings are generalizable.

\section{Conclusions}

The literature suggests that positive relationships at work are likely to be valuable and desired by individuals. The present study found that positive relationships are valuable to managers, and indeed, and can play interesting direct and indirect effects on the organizational trust of managers, especially those higher up the managerial hierarchy. These relationships are also positive towards aiding work-life balance, through providing additional psychological resources through greater friendships and support, which ultimately provide opportunities for better management of work and life roles. Fundamentally, healthy organizations have been promoted as an important and valuable way for organizations to signal they care and support the well-being and work attitudes of employees [1,3], and we found here that encouraging and supporting positive relationships is likely to be key. Not only do these relationships build job attitudes like trust, but they also facilitate well-being via work-life balance. Importantly, organizations that seek to develop and encourage the relationships between managers and subordinates—and others within an organization-are likely to create an environment where positive relationships are fostered, well-being and job attitudes improve, and, ultimately, performance will thrive.

Author Contributions: Conceptualization: J.H., A.D.F.; Data curation: J.H., U.D.; Investigation: J.H., U.D.; Methodology: J.H.; Supervision: A.D.F.; Writing—original draft: J.H., A.D.F.; Writing—review \& editing: J.H., A.D.F., U.D.

Funding: This research was funded by the National Science Challenge (New Zealand): Science for Technological Innovation (Kia Kotahi Mai: Te Ao P taiao me Te Ao Hangarau).

Conflicts of Interest: The authors declare no conflicts of interest.

\section{References}

1. Di Fabio, A. The psychology of sustainability and sustainable development for well-being in organizations. In Arcangeli, G.; Giorgi, G.; Mucci, N.; Bernaud, J.L.; Di Fabio, A. Emerging and re-emerging organizational features, work transitions and occupational risk factors: The good, the bad, the right. An interdisciplinary perspective. Front. Psychol. Sect. Org. Psychol. 2017, 8, 1534. [CrossRef]

2. Roche, M.; Haar, J.M.; Luthans, F. Mindfulness, psychological capital and leader wellbeing. J. Occup. Health Psychol. 2014, 19, 476-489. [CrossRef]

3. Di Fabio, A.; Palazzeschi, L.; Bucci, O. In an unpredictable and changing environment: intrapreneurial self-capital as a key resource for life satisfaction and flourishing. Front. Psychol. Sect. Org. Psychol. 2017, 8, 1819. [CrossRef] 
4. Ten Brummelhuis, L.L.; Haar, J.; Roche, M. Does family life help to be a better leader? A closer look at cross-over processes from leaders to followers. Personal. Psychol. 2014, 67, 917-949. [CrossRef]

5. Johnson, S.K. I second that emotion: Effects of emotional contagion and affect at work on leader and follower outcomes. Leader. Quart. 2008, 19,1-19. [CrossRef]

6. Sy, T.; Côté, S.; Saavedra, R. The contagious leader: Impact of the leader's mood on the mood of group members, group affective tone, and group processes. J. Appl. Psychol. 2005, 90, 295-305. [CrossRef]

7. Seligman, M.E.; Csikszentmihalyi, M. Positive Psychology: An Introduction. Am. Psychol. 2000, 55, 5-14. [CrossRef]

8. Di Fabio, A. Positive Relational Management for healthy organizations: Psychometric properties of a new scale for prevention for workers. Front. Psychol. Organ Psychol. 2016, 7, 1523. [CrossRef]

9. Henry, J. The healthy organization. In Research Companion to Organizational Health Psychology; Antoniou, A.S.G., Cooper, C.L., Eds.; Edward Elgar: Cheltenham, UK, 2005; pp. 382-391.

10. Seligman, M.E.P. Positive psychology, positive prevention and positive therapy. In Handbook of Positive Psychology; Snyder, C.R., Lopez, S.J., Eds.; Oxford University Press: New York, NY, USA, 2002; pp. 3-9.

11. Di Fabio, A. Career counselling and positive psychology in the 21st century: New constructs and measures for evaluating the effectiveness of intervention. J. Couns. 2014, 1, 193-213.

12. Carr, S.C.; Maleka, M.; Meyer, I.; Barry, M.L.; Haar, J.; Parker, J.; Young-Hausner, A. How can wages sustain a living? By getting ahead of the curve. Sustain. Sci. 2018, 13, 901-917. [CrossRef]

13. United Nations. About the Sustainable Development Goals. 2018. Available online: https://www.un.org/ sustainabledevelopment/sustainable-development-goals/ (accessed on 13 June 2019).

14. Di Fabio, A. Positive Healthy Organizations: Promoting well-being, meaningfulness and sustainability in organizations. In Arcangeli, G.; Giorgi, G.; Mucci, N.; Bernaud, J.L.; Di Fabio, A. Emerging and re-emerging organizational features, work transitions and occupational risk factors: The good, the bad, the right. An interdisciplinary perspective. Front. Psychol. Sect. Org. Psychol. 2017, 8, 1938. [CrossRef]

15. Di Fabio, A.; Rosen, M.A. Opening the Black Box of Psychological Processes in the Science of Sustainable Development: A New Frontier. Eur. J. Sustain. Dev. Res. 2018, 2, 47. [CrossRef]

16. Di Fabio, A.; Saklofske, D.H. Promoting individual resources: The challenge of trait emotional intelligence. Personal. Individ. Differ. 2014, 65, 19-23. [CrossRef]

17. Di Fabio, A.; Kenny, M.E. The contribution of emotional intelligence to decisional styles among Italian high school students. J. Career Assess 2012, 20, 404-414. [CrossRef]

18. Di Fabio, A.; Kenny, E.M. From decent work to decent lives: Positive Self and Relational Management (PS\&RM) in the twenty-first century. Front. Psychol. Sect. Org. Psychol. 2016, 7, 361. [CrossRef]

19. Di Fabio, A.; Kenny, M.E. Promoting well-being: The contribution of emotional intelligence. Front. Psychol. Sect. Org. Psychol. 2016, 7, 1182. [CrossRef]

20. Di Fabio, A.; Peiró, J.M. Human Capital Sustainability Leadership to promote sustainable development and healthy organizations: A new scale. Sustainability 2018, 10, 2413. [CrossRef]

21. Henao-Zapata, D.; Peiró, J.M. The importance of empowerment in entrepreneurship. In Inside the Mind of the Entrepreneur: Cognition, Personality Traits, Intention and Gender Behavior; Tur Porcar, A., Soriano, D.R., Eds.; Springer: Valencia, Spain, 2018; pp. 185-206.

22. Tetrick, L.E.; Peiró, J.M. Occupational Safety and Health. In The Oxford Handbook of Organizational Psychology; Kozlowski, S.W.J., Ed.; Oxford University Press: Oxford, UK, 2012; Volume 2.

23. Di Fabio, A.; Tsuda, A. The psychology of harmony and harmonization: Advancing the perspectives for the psychology of sustainability and sustainable development. In A. Di Fabio (Ed.), Psychology of Sustainability and Sustainable Development. Sustainability 2018, 10, 4726. [CrossRef]

24. Di Fabio, A.; Kenny, M.E. The contributions of emotional intelligence and social support for adaptive career progress among Italian youth. J. Career Dev. 2015, 42, 48-59. [CrossRef]

25. Hage, S.M.; Romano, J.L.; Conyne, R.K.; Kenny, M.; Matthews, C.; Schwartz, J.P.; Waldo, M. Best practice guidelines on prevention practice, research, training, and social advocacy for psychologists. Counsel. Psychol. 2007, 35, 493-566. [CrossRef]

26. Di Fabio, A.; Saklofske, D.H. Positive relational management for sustainable development: Beyond personality traits-The contribution of emotional intelligence. Sustainability 2019, 11, 330. [CrossRef] 
27. Di Fabio, A.; Kenny, M.E. Resources for enhancing employee and organizational well-being beyond personality traits: The promise of Emotional Intelligence and Positive Relational Management. Personal. Individ. Differ. 2019. [CrossRef]

28. Colquitt, J.A.; Scott, B.A.; LePine, J.A. Trust, trustworthiness and trust propensity: A meta-analytic test of their unique relationships with risk taking and job performance. J. Appl. Psychol. 2007, 92, 909-927. [CrossRef]

29. Haar, J.M. Testing a new measure of work-life balance: A study of parent and non-parent employees from New Zealand. Int. J. Hum. Res. Manag. 2013, 24, 3305-3324. [CrossRef]

30. Haar, J.; Roche, M.A.; ten Brummelhuis, L. A daily diary study of work-life balance in managers: Utilizing a daily process model. Int. J. Hum. Res. Manag. 2018, 29, 2659-2681. [CrossRef]

31. Haar, J.M.; Russo, M.; Sune, A.; Ollier-Malaterre, A. Outcomes of work-life balance on job satisfaction, life satisfaction and mental health: A study across seven cultures. J. Vocat. Behav. 2014, 85, 361-373. [CrossRef]

32. Hayes, A.F. Partial, conditional and moderated moderated mediation: Quantification, inference and interpretation. Commun. Monogr. 2018, 85, 4-40. [CrossRef]

33. Di Fabio, A.; Maree, J.G. Group-based life design counseling in an Italian context. J. Vocat. Behav. 2012, 80, 100-107. [CrossRef]

34. Di Fabio, A. Positive Relational Management Scale to detect positivity and complexity. Couns. G. Ital. Ric. Appl. 2015.

35. Di Fabio, A.; Bucci, O. Affective profiles in Italian high school students: Life satisfaction, psychological well-being, self-esteem and optimism. Front. Psychol. 2015, 6, 1310. [PubMed]

36. Hobfoll, S.E. Conservation of Resources: A new attempt at conceptualizing stress. Am. Psychol. 1989, 44, 513-524. [CrossRef]

37. Hobfoll, S.E. The influence of culture, community and the nested-self in the stress process: Advancing conservation of resources theory. Appl. Psychol. Int. Rev. 2001, 50, 337-421. [CrossRef]

38. Arnoux-Nicolas, C.; Sovet, L.; Lhotellier, L.; Di Fabio, A.; Bernaud, J.L. Perceived work conditions and turnover intentions: The mediating role of meaning of life and meaning of work. Front. Psychol. 2016, 7, 704. [CrossRef] [PubMed]

39. Burke, C.S.; Sims, D.E.; Lazzara, E.H.; Salas, E. Trust in leadership: A multi-level review and integration. Lead. Quart. 2007, 18, 606-632. [CrossRef]

40. McAllister, D.J. Affect-and cognition-based trust as foundations for interpersonal cooperation in organizations. Acad. Manag. J. 1995, 38, 24-59.

41. Robinson, S.L. Trust and breach of the psychological contract. Adm. Sci. Quart. 1996, 41, 574-599. [CrossRef]

42. Bunker, B.B.; Alban, B.T.; Lewicki, R.J. Ideas in currency and OD practice: has the well gone dry? J. Appl. Behav. Sci. 2004, 40, 403-422. [CrossRef]

43. Guerrero, S.; Herrbach, O. La confiance organisationnelle au cœur de l'échange social: et si bien traiter ses employés était payant? Relat. Ind. Ind. Relat. 2009, 64, 6-26. [CrossRef]

44. Rhoades, L.; Eisenberger, R. Perceived organizational support: A review of the literature. J. Appl. Psychol. 2002, 87, 698-714. [CrossRef]

45. Haar, J.M.; Spell, C.S. Programme knowledge and value of work-family practices and organizational commitment. Int. J. Hum. Res. Manag. 2004, 15, 1040-1055. [CrossRef]

46. Blau, P.M. Exchange and Power in Social Life; Wiley: New York, NY, USA, 1964.

47. Haar, J.M. Challenge and hindrance stressors in New Zealand: Exploring social exchange theory outcomes. Int. J. Hum. Res. Manag. 2006, 17, 1942-1950. [CrossRef]

48. Russo, M.; Shteigman, A.; Carmeli, A. Workplace and family support and work-life balance: Implications for individual psychological availability and energy at work. J. Posit. Psychol. 2016, 11, 173-188. [CrossRef]

49. Haar, J.; Carr, S.; Parker, J.; Arrowsmith, J.; Hodgetts, D.; Alefaio-Tugia, S. Escape from working poverty: Steps toward sustainable livelihood. Sustainability 2018, 10, 4144. [CrossRef]

50. Haar, J.M.; Sune, A.; Russo, M.; Ollier-Malaterre, A. A cross-national study on the antecedents of work-life balance from the fit and balance perspective. Soc. Indic. Res. 2019, 142, 261-282. [CrossRef]

51. Greenhaus, J.; Allen, T. Work-family balance: A review and extension of the literature. In Handbook of Occupational Health Psychology; Quick, J.C., Tetrick, L.E., Eds.; American Psychological Association: Washington, DC, USA, 2011. 
52. Barnett, R.C.; Hyde, J.S. Women, men, work and family: An expansionist theory. Am. Psychol. 2001, 56, 781-796. [CrossRef] [PubMed]

53. Haar, J.; Roche, M.; Brougham, D. Indigenous insights into ethical leadership: A study of Māori leaders. J. Bus. Ethics 2018. [CrossRef]

54. Haar, J.; Brougham, D.; Roche, M.A.; Barney, A. Servant leadership and work engagement: The mediating role of work-life balance. New Zealand J. Hum. Res. Manag. 2017, 17, 56-72.

55. Jaques, E. Requisite Organization: A Total System for Effective Managerial Organization and Managerial Leadership for the 21st Century; Routledge: Abingdon, UK, 2017.

56. Roche, M.; Haar, J.M. Work-family interface predicting needs satisfaction: The benefits for senior management. J. Soc. Behav. Res Bus. 2010, 1, 12-23. [CrossRef]

57. Schieman, S.; Reid, S. Job authority and health: Unrevealing the competing suppression and explanatory influences. Soc. Sci. Med. 2009, 69, 1616-1624. [CrossRef]

58. Klein, K.J.; Ziegert, J.C.; Knight, A.P.; Xiao, Y. Dynamic delegation: Shared, hierarchical, and deindividualized leadership in extreme action teams. Adm. Sci. Quart. 2006, 51, 590-621. [CrossRef]

59. Warr, P. Work, well-being and mental health. In Handbook of Work Stress; Barling, J., Kelloway, E.K., Frone, M.R., Eds.; Sage Publications: Thousand Oaks, CA, USA, 2005; pp. 547-574.

60. Muller, D.; Judd, C.M.; Yzerbyt, V.Y. When moderation is mediated and mediation is moderated. J. Pers. Soc. Psychol. 2005, 89, 852-863. [CrossRef]

61. Haar, J.M.; Spell, C.S. Factors affecting employer adoption of drug testing in New Zealand. Asia Pacific J. Hum. Res. 2007, 45, 200-217. [CrossRef]

62. Haar, J.; White, B. Corporate entrepreneurship and employee retention in New Zealand: The moderating effects of information technology. Hum. Res. Manag. J. 2013, 23, 109-125. [CrossRef]

63. Ng, T.W.; Feldman, D.C. The relationships of age with job attitudes: A meta-analysis. Pers. Psychol. 2010, 63, 677-718. [CrossRef]

64. Bowling, N.A.; Eschleman, K.J.; Wang, Q.; Kirkendall, C.; Alarcon, G. A meta-analysis of the predictors and consequences of organization-based self-esteem. J. Occup. Organ. Psychol. 2010, 83, 601-626. [CrossRef]

65. Williams, L.J.; Vandenberg, R.J.; Edwards, J.R. 12 Structural equation modeling in management research: A guide for improved analysis. Acad. Manag. Ann. 2009, 3, 543-604. [CrossRef]

66. Hair, J.F.; Black, W.C.; Babin, B.J.; Anderson, R.E. Multivar. Anal, 7th ed.; Prentice Hall: Upper Saddle River, NJ, USA, 2010; ISBN 978-1-292-02190-4.

67. Haar, J.; Schmitz, A.; Di Fabio, A.; Daellenbach, U. The role of relationships at work and happiness: A moderated moderated mediation study of New Zealand managers. Sustainability 2019, 11, 3443.

68. Wayne, S.J.; Lemmon, G.; Hoobler, J.M.; Cheung, G.W.; Wilson, M.S. The ripple effect: A spillover model of the detrimental impact of work-family conflict on job success. J. Organ. Behav. 2017, 38, 876-894. [CrossRef]

69. Evans, M.A. Monte Carlo study of the effects of correlated method variance in moderated multiple regression analysis. Organ. Behav. Hum. Decis. Process. 1985, 36, 305-323. [CrossRef]

70. Hayes, A.F.; Montoya, A.K.; Rockwood, N.J. The analysis of mechanisms and their contingencies: PROCESS versus structural equation modeling. Aust. Mark. J. 2017, 25, 76-81.

71. Podsakoff, P.M.; MacKenzie, S.B.; Lee, J.Y.; Podsakoff, N.P. Common method biases in behavioral research: A critical review of the literature and recommended remedies. J. Appl. Psychol. 2003, 88, 879-903. [CrossRef] [PubMed]

72. Lindell, M.K.; Whitney, D.J. Accounting for common method variance in cross-sectional research designs. J. Appl. Psychol. 2001, 86, 114-121. [CrossRef] [PubMed]

73. Raskin, R.N.; Terry, H. A principal components analysis of the Narcissistic Personality Inventory and further evidence of its construct validity. J. Pers. Soc. Psychol. 1988, 54, 890-902. [CrossRef] [PubMed]

(C) 2019 by the authors. Licensee MDPI, Basel, Switzerland. This article is an open access article distributed under the terms and conditions of the Creative Commons Attribution (CC BY) license (http://creativecommons.org/licenses/by/4.0/). 